\title{
El Incremento de las Tasas Académicas Universitarias Españolas como Mecanismo de Nueva Gestión Pública. Estudio Territorial del Establecimiento de los Precios Públicos
}

\author{
The Increase in Spanish Academic University Fees as a \\ Mechanism of New Public Management. Territorial Study of the \\ Establishment of Public Prices
}

\author{
Luján Lázaro Herrero * \\ Universidad de Salamanca, España
}

\begin{abstract}
Este trabajo tiene por objeto abordar el cambio que las universidades públicas españolas han experimentados actualmente respecto a sus parámetros de financiación. Toma como eje principal el incremento de las tasas académicas introducido a partir del año 2012, entendiendo este mecanismo como un síntoma y una señal de la aplicación de elementos de nueva gestión pública al sector de la educación superior, una medida utilizada para empoderar a los estudiantes y a sus familias como consumidores. A través de un estudio analítico de corte cuantitativo, que maneja estadísticas del Ministerio de Educación, Cultura y Deporte de precios públicos de estudios de grado correspondientes al curso 2017/2018, constatamos la disparidad existente en la fijación de precios públicos entre Comunidades Autónomas, propiciada por el establecimiento de grados de experimentalidad, así como la potenciación de una vía de financiación privada a través de la partida de tasas académicas. Resalta también el establecimiento de un sistema de precios que penaliza, pagando más, al alumno que no alcanza los resultados académicos esperados. Todo ello define un contexto marcado por la mercantilización de la educación
\end{abstract}

Descriptores: Financiación de la educación; Precios; Universidad; Gestión de la educación; Recursos económicos.

\begin{abstract}
This paper aims to address the changes that Spanish public universities have undergone with respect to their financing parameters. It takes as its main axis the increase in academic fees that was introduced starting in 2012, understanding this mechanism as a symptom and a sign of the application of elements of new public management to the higher education sector, a measure used to empower students and their families as consumers. Through a quantitative analytical study, using statistics from the Ministry of Education, Culture and Sport of the public prices of undergraduate studies corresponding to academic year 2017/2018, we note the disparity between Autonomous Communities in the setting of public prices, caused by the establishment of different gradations according to the experimental nature of the studies in question, as well as the fostering of a means of private financing through the heading of academic fees. The study also highlights the establishment of a pricing system that penalizes students who do not achieve the expected academic results, by obliging them to pay more. All this defines a context marked by the commodification of education.
\end{abstract}

Keywords: Educational finance; Prices; Universities; Educational management; Economic resources.

*Contacto: lujan@usal.es

ISSN: 1696-4713

www.rinace.net/reice/

revistas.uam.es/reice
Recibido: 4 de noviembre 2018

$1^{\text {a }}$ Evaluación: 3 de enero 2019

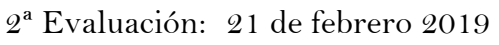

Aceptado: $\quad$ 14 de marzo 2019 


\section{Introducción}

La narrativa de la "Nueva Gestión Pública", NPM -según sus siglas en inglés- irrumpe en el panorama educativo a través de políticas neoliberales cuyo impacto invita a detenernos en el cambio que se está produciendo de la visión de la educación como un bien social hacia una concepción puramente instrumental (Giroux, 2016) de la misma. Reflexión que nos lleva a preguntarnos si la educación superior representa aún hoy un bien público o ha adquirido tintes propios del privado (Kehm, 2012). Cuestión ésta que enmarcamos dentro de un contexto definido por la quiebra del "sentido de la dicotomía entre lo público y lo privado” (Fernández-González, 2016, p. 2), a partir del cual, la gestión estatal toma tintes propios del mundo empresarial.

Desde un punto de vista económico, y haciendo uso principalmente de las ideas plasmadas por Samuelson ${ }^{1}$, considerado el padre de la teoría de las finanzas públicas, un bien o servicio público es aquel que se consume en condición de no rivalidad, es decir, que todos los ciudadanos pueden acceder a él sin que se admita la posibilidad de exclusión. Estaría regulado por el Estado y no por el mercado y se distanciaría del privado, precisamente, por la condición exclusiva de éste.

Así pues, dentro del marco fijado por la economía de mercado, se comienza a concebir lo educativo como mercancía, como un producto más que se compra y se vende y que, por lo tanto, a través de él, se pueden obtener unas ganancias. Así lo constatan autoras como Kehm (2012) al afirmar, respecto a la educación universitaria, que “(...) se está dando un giro paradigmático en el que, por una serie de razones, se está caracterizando a la educación superior como un bien que puede ser comprado o vendido en los mercados" (p. 25).

Identifica Verger (2013) la mercantilización educativa como "un fenómeno multidimensional constituido por procesos de liberalización, privatización y comercialización" (p. 284). El principio de competencia entre instituciones vendría de la mano de la liberalización e introduce la libertad de elección como elemento mercantil. El prestigio académico ya no es el capital más perseguido por las universidades, instituciones que en estos momentos ponen su mira en bienes como los recursos financieros y la captación de alumnos, y es que es un hecho que la "competición por financiación se está convirtiendo en un proceso, en una práctica política que está "re/de/ formando" la educación superior" (Daza et al., 2015, p. 149). La lucha y competencia entre los diferentes estamentos educativos refleja la batalla por la gestión del conocimiento (Espejo y Lázaro Herrero, 2016) en la que, en los últimos años, de alguna manera, se ven inmersas las instituciones de educación superior.

Es precisamente el cambio en los parámetros de financiación de las universidades públicas españolas el objeto de este trabajo que, toma como unidad de estudio la subida que en los últimos años han experimentado las tasas académicas públicas. Entendemos este mecanismo de aumento del coste académico en los términos que recogen Ferlie, Musselín y Andresani (2012), los cuales presentan este hecho como un síntoma y una señal de la aplicación de elementos de nueva gestión pública al sector de la educación superior, un mecanismo utilizado "para empoderar a los estudiantes como consumidores y elevar la

${ }^{1}$ Premio nobel de economía en 1970 
calidad de la docencia” (p. 150). Trabajos antecesores como el de Escardíbul y otros (2013), constatan la dispersión en cuanto al precio de matrícula, por Comunidades Autónomas, que comienza a vislumbrarse a partir de los cambios normativos introducidos en el año 2012, cuestión que no había sucedido anteriormente, ya que los estudios realizados al respecto mostraban un nivel bajo de disparidad de precios entre comunidades.

Somos conscientes que todo trabajo en el que se abordan cuestiones de tasas académicas y precios públicos ha de ir acompañado de un estudio respecto a la política de becas y ayudas públicas. Por razones de espacio no reflejamos estos aspectos a sabiendas de la importancia que tienen tanto las ayudas financieras como los precios académicos fijados ya que son dos variables clave en el acceso y en la permanencia del alumno en el sistema universitario. En este sentido, estudios como el realizado por el sindicato Comisiones Obreras (CCOO, 2016) en el que no sólo se muestra un análisis comparativo de los precios de las tasas académicas a nivel europeo, sino que también realiza el correspondiente trabajo respecto a becas, ayudas y beneficios fiscales en dicho territorio, puede servirnos de ilustración. Destaca en este sentido, cómo el aumento de las tasas académicas ha ido en paralelo a la implantación de un severo sistema de adjudicación de ayudas y becas de estudio que dificultad el acceso equitativo a la educación superior. De igual forma, entendemos que sería conveniente ampliar el estudio y abordar la cuestión atendiendo a los precios de los másteres universitarios que, también se contemplan como titulaciones oficiales. Hemos excluido esta unidad de análisis, nuevamente, por cuestión de delimitación del objeto de estudio, no sin incidir en la pertinencia como prospección investigadora.

El artículo que presentamos a continuación está organizado en tres partes. La primera describe la situación en la que se encuentra la universidad española en cuanto a su estructura financiera bajo las premisas de los nuevos mecanismos de gestión pública. En segundo lugar, se constata, la partida "tasas públicas" como una fuente de financiación privada. Y, por último, mediante un estudio estadístico, se comprueba cómo el parámetro de experimentalidad es la puerta que posibilita la gran heterogeneidad y dispersión autonómica y, se constata la penalización económica del alumno por falta de rendimiento como un mecanismo de disuasión que va a contribuir a aumentar el nivel de ingresos en las arcas universitarias.

\section{Revisión teórica}

\subsection{El impacto de la Nueva Gestión Pública en los estandartes financieros}

La gobernanza universitaria es indisociable de aspectos como la financiación. No en vano, Llinás-Audet, Girotto y Solé (2011) ya resaltaron en su momento, el cambio en las pautas de financiación como unos de los retos más eminentes a los que tenían que hacer frente las instituciones universitarias marcadas por el discurso de la excelencia académica (Lázaro Herrero, 2015).

Autores como Schwartz (2007) han criticado el anquilosamiento de las universidades públicas españolas respaldando la idea de la necesidad imperante de la transformación de su sistema de incentivos. La NPM "se caracteriza por la financiación basada en indicadores de rendimiento" (Girotto, Mundet y Llinás-Audet, 2013, p. 97) y, propone una subvención pública supeditada a resultados (ayudas públicas ligadas al esfuerzo y éxito de los favorecidos), así como la atracción de empresas privadas. Se trataría de conseguir una 
mayor competencia entre instituciones públicas e instituciones privadas, como un acicate para que las públicas salieran de su estancamiento financiero debido principalmente a su incapacidad organizativa; y una mayor variedad y calidad de la oferta de formación e investigación por parte de las universidades privadas.

Bajo este clima imperado por el reto de excelencia, se apela a los beneficios de una educación superior orientada hacia el mercado. Es más, es fácil encontrar manifiestos que afirmaban y reclamaban que "Europa y todos los países deberían desmantelar sus sistemas de educación superior con gran apoyo financiero del Estado e imitar a EEUU" (López Segrera, 2009, p. 525). El discurso que tiende a desvalorizar a las universidades españolas y a cuestionar su calidad, se fija en el modelo de universidad norteamericana como referente por su visibilidad en los rankings internacionales. Un modelo en el que las universidades públicas sólo reciben una pequeña parte de sus fondos de las Administraciones federal y estatal y en el que, la "búsqueda continua de financiación privada y pública es un incentivo para mantener los niveles más altos de excelencia, ya que de otro modo los fondos disponibles se asignan a otros centros, atendiendo a criterios competitivos y de mérito" (Canosa, 2007, p. 2).

Ahora bien, como sabemos, la financiación pública es la principal fuente que sustenta a las universidades, cuestión que ha contribuido en los últimos años, a una progresión, sin precedentes, de este sistema y que se ha visto arropado "por un auge de crecimiento económico experimentado por el país hasta el año 2007, momento en el que la crisis económica se hace patente" (Escardíbul y Pérez, 2013, p. 3). Son precisamente, los acontecimientos financieros acaecidos a nivel mundial, los que instigan a los diferentes gobiernos a plantearse una reformulación de los mecanismos de financiación en este terreno. La búsqueda de sostenibilidad financiera pasaría por el incremento de las fuentes de financiación privada y por el control y reducción de costes (Aguilá, 2016). Destaca el Informe Conocimiento y Desarrollo (2015), que maneja datos del año 2014, cómo la mayor parte de los ingresos de las universidades públicas en España, alrededor de un 63\%, procedió de las transferencias corrientes recibidas por las respectivas comunidades, a las que se les suma las recibidas por capital, destinadas a inversiones, lo que da como resultado algo más $75 \%$ de ingresos. El 23\% del total de los ingresos líquidos provino del apartado de tasas académicas.

Como acabamos de ver, las dos principales fuentes de ingresos de las universidades públicas españolas corresponden a las transferencias corrientes recibidas de las Administraciones Autonómicas y a la partida de tasas, precios públicos y otros ingresos. Es cada gobierno regional el que tiene la potestad para fijar las fórmulas en el reparto de recursos financieros, obedeciendo a criterios de coste, input (tamaño de universidades) y de output (rendimiento), existiendo mecanismos de financiación complementaria que dependen de objetivos establecidos en investigación, docencia y gestión. Los recortes presupuestarios y el aumento experimentado por los precios públicos en los últimos años, han propiciado que "respecto a 2009, el peso relativo de las transferencias se ha reducido (en torno a 5,5 puntos porcentuales), mientras que el del capítulo de tasas, precios públicos y otros ingresos se ha incrementado unos siete puntos" (Informe CyD, 2015, p. 62).

La realidad muestra un panorama muy heterogéneo y una disparidad importante respecto al esfuerzo financiero realizado por las Comunidades Autónomas en este sentido, lo que se manifiesta en las propias instituciones universitarias que están abocadas a competir entre ellas, tanto en el reparto público como en el capítulo de ingresos privados, siendo 
éste quizás el escenario donde más margen de maniobra tienen las universidades para la búsqueda de recursos económicos.

El régimen competitivo de financiación se ve reflejado, entre otros, en la captación de estudiantes en un mercado abierto, donde "todas las ofertas educativas públicas y privadas compiten por atraer estudiantes" (Guerrero, 2012, p. 159). El alumno y sus familias se convierten en consumidores de educación. El Estado, a través de la transferencia de competencias en materia de universidad a las Comunidades Autónomas permite que éstas se constituyan en un régimen de cuasi mercado en el que incorporan, a este servicio público, mecanismos de mercado como son, las reglas de financiamiento. Así pues, los gobiernos regionales no establecen sus precios en función de la oferta y la demanda, sino que tienen libertad para fijarlos en el marco de una estructura fuertemente regulada y propician la “(...) competición entre proveedores" (Verger, Bonal y Zancajo, 2016, p. 2) por la captación de fondos.

\subsection{El aumento de las tasas académicas como fuente de financiación privada: Empoderamiento del alumno como consumidor de educación}

Destacaba San Segundo (1999) el hecho de que la elevación de la contribución de los usuarios al servicio de financiación de las universidades, mediante precios, y la implantación de programas de préstamos financieros a los estudiantes y familias, eran dos tendencias en los modelos de financiación que ya se apreciaban como medias de reforma en países de la OCDE.

Fue la aprobación del Real Decreto-ley 14/2012, de 20 de abril, de medidas urgentes de

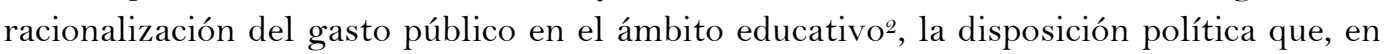
España, supuso la apertura hacia un panorama de lo más heterogéneo en cuanto a precios públicos universitarios. Diversidad que ya venía acentuada entre comunidades no sólo por cuestiones históricas (momento en el que se adquieren competencias en materia universitaria) si no también, por la manera en la que se ha establecido la experimentalidad de los estudios.

A partir de este momento, bajo el amparo de la nueva normativa y la premisa de vincular el precio con el coste real de los estudios, se experimenta un notorio incremento de las tasas académicas con respecto a los cursos anteriores. Así, comunidades como Cataluña, Madrid y Castilla y León disparan de manera desorbitada el precio medio del crédito matriculado por primera vez, colgándose el cartel de "las más caras". tal y como se puede percibir en el gráfico 1 que toma como referencia el curso 2000/2001 (se ha pretendido mostrar los datos del curso 2002/2003 para así establecer diez años de diferencia, pero no ha sido posible ya que no constan, siendo la siguiente referencia facilitada el curso 2004/2005) y establece un periodo de evolución de once años. Cierto es que estas comunidades, las que, en un principio, dispararon el precio del crédito, en los últimos años, han hecho una revisión de los mismos a la baja. Aun así, siguen ocupando la primera posición en cuanto a "caras".

\footnotetext{
${ }^{2}$ Establece respecto a las enseñanzas de grado que los precios públicos cubrirán entre el 15 por 100 y el 25 por 100 de los costes en primera matrícula; entre el 30 por 100 y el 40 por 100 de los costes en segunda matrícula; entre el 65 por 100 y el 75 por 100 de los costes en la tercera matrícula; y entre el 90 por 100 y el 100 por 100 de los costes a partir de la cuarta matrícula. Esta regla se mantiene para las enseñanzas de máster que habilita para el ejercicio de actividades profesionales y cambia respeto a las enseñanzas de máster no habilitantes donde los precios públicos cubrirán entre el 40 por 100 y el 50 por 100 de los costes en primera matrícula; y entre el 65 por 100 y el 75 por 100 de los costes a partir de la segunda matrícula.
} 


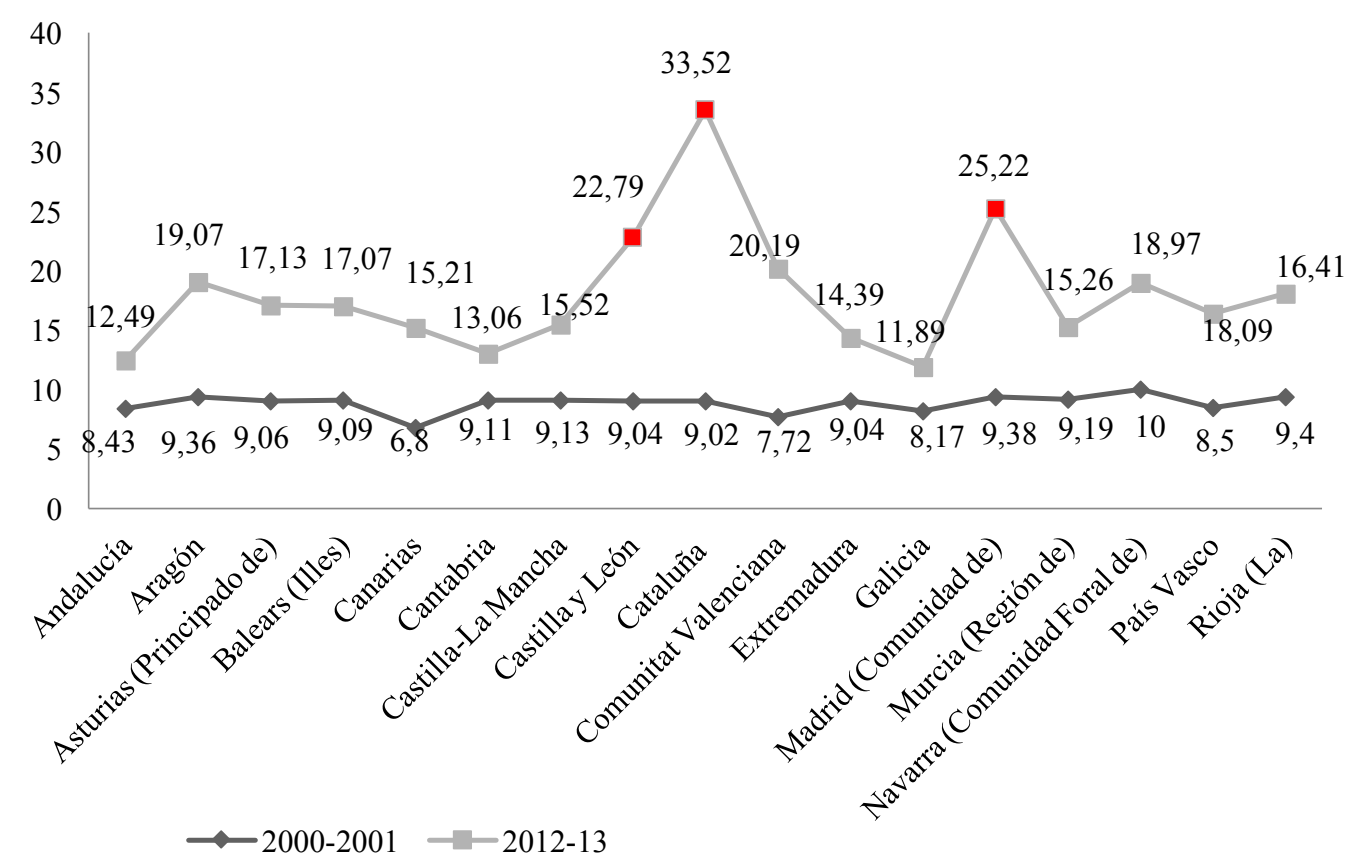

Figura 1. Evolución del precio medio en euros del crédito matriculado por primera vez en titulaciones de primer y segundo ciclo (curso 2000/2001) y de grado (curso

$$
\text { 2012/2013 }
$$

Fuente: Elaboración propia a partir de datos estadísticos MEC.

La evolución de los precios medios del crédito matriculado por primera vez a partir del curso 2012/2013 ha ido creciendo progresivamente, aunque este incremento no ha sido muy alto. Fue el citado curso el que supuso el acicate para establecer la "gran subida" de precios.

La contribución de los estudiantes y sus familias a la financiación privada de las universidades, es una cuestión objeto de debate en toda Europa (Escardíbul y Pérez, 2013), de igual modo que "la transferencia del peso de la financiación a los individuos y a sus familias (...) es un enfoque político controvertido" (Eurydice, 2011, p. 12) a partir del cual, la educación superior estaría catalogada como un bien privado, en el marco de una economía de mercado, y sería el estudiante y su familia el que afrontara los costes de dicha educación (Sanz-Magallón, Schwartz y Morales, 2009).

El peso que tenga la financiación pública en cada uno de los países, va a condicionar el modelo de tasas que se aplica. Como se observa en la tabla 1, en un número importante de países europeos, entre los que destacan los nórdicos, la financiación universitaria es completamente pública, lo que se traduce en matrículas gratuitas o en el pago de unas tasas mínimas. Por su parte, aquellos países que establecen precios de matrícula muy elevados, articulan sistemas de contribución económica que diferencian programas, tipos de estudiantes, y oferta educativa. No situamos directamente a España en esta franja, pero sí lo hacemos en aquella que engloba a países que han elevado sus tasas académicas en los últimos años, donde la educación superior ha sido considerada tradicionalmente como un "bien público" y, se está iniciando un camino hacia el aumento de recursos obtenidos por vías privadas, entre ellas, el desembolso individual del alumno en concepto de tasas académicas. En la actualidad, se verifica que el alumno español hace frente al pago de unos 
precios académicos que están situados en niveles muy elevados dentro del panorama europeo (cuadro 1).

Cuadro 1. Precio medio de matrícula de primer curso en estudios de grado. 37 países europeos

\begin{tabular}{|c|c|c|}
\hline Precio & & PAÍSES \\
\hline Gratuita & $\begin{array}{l}8 \text { países }+ \\
\text { región }\end{array}$ & $\begin{array}{l}\text { Dinamarca, Alemania, Grecia, Noruega, Suecia, Chipre, Malta, } \\
\text { Finlandia, Reino Unido (Escocia) }\end{array}$ \\
\hline $\begin{array}{l}\text { Entre } 1 €- \\
100 €\end{array}$ & 4 países & República Checa, Eslovenia, Eslovaquia y Polonia \\
\hline $\begin{array}{l}\text { Entre } 101 €- \\
\quad 1.000 €\end{array}$ & 12 países & $\begin{array}{l}\text { Bélgica, Bulgaria, Francia, Croacia, Luxemburgo, Montenegro, } \\
\text { Serbia, Turquía, Bosnia y Herzegovina, Austria, República } \\
\text { Yugoslava de Macedonia, Rumanía }\end{array}$ \\
\hline $\begin{array}{l}\text { Entre } 1.001 \\
-3.000 €\end{array}$ & 8 países & $\begin{array}{l}\text { Irlanda, España, Italia, Portugal, Suiza, Liechtenstein, Hungría y } \\
\text { Países Bajos }\end{array}$ \\
\hline $\begin{array}{c}\text { Entre } 3.001 \\
-5.000 € \\
\end{array}$ & $\begin{array}{l}1 \text { país }+ \\
\text { región }\end{array}$ & Reino Unido (Norte de Irlanda), Letonia \\
\hline $\begin{array}{l}\text { Más de } \\
5.000 €\end{array}$ & 4 países & Reino Unido (Inglaterra y Gales), Estonia, Islandia y Lituania \\
\hline
\end{tabular}

Fuente: Elaboración propia a partir de los datos de Eurydice (2016).

Si analizamos el esfuerzo que supone para las familias españolas el pago de las tasas públicas respecto a la capacidad de renta en cada Comunidades Autónomas, nos encontramos con que dichos esfuerzos también son diferentes entre las regiones y que, a su vez, no guardan proporcionalidad respecto a los niveles de renta per cápita. En este sentido, destaca el informe CRUE (2016), respecto al curso 2014/2015, cómo Cataluña encabeza el nivel de esfuerzo con un 7,5\% sobre su renta per cápita y en el extremo opuesto se encontraría el País Vasco, con un 4,4\% de esfuerzo. Ambas comunidades presentan niveles superiores de renta per cápita a la media de España mientras que Extremadura, realizaría un esfuerzo del 5,9\% ocupando la última posición respecto al nivel de renta per cápita, siendo ésta prácticamente correspondiente a la mitad de la de un ciudadano que habita en la comunidad del País Vasco. Podemos observar que no hay una proporcionalidad que equipare el nivel de renta familiar con su esfuerzo de desembolso económico en cuanto a pago de tasas académicas, aspecto éste que pone en entre dicho el principio de equidad que ha de ser garantizado en el acceso a un servicio educativo de carácter público.

\section{Método}

A continuación, se presenta un estudio analítico, de corte cuantitativo, que utiliza las estadísticas publicadas por el Ministerio de Educación, Cultura y Deporte, en el apartado de precios públicos universitarios para el curso 2017/2018.

La población del análisis la conforman las 17 Comunidades Autónomas de España con competencia en materia universitaria, y la muestra estaría formada por los estudios de grado oficiales. Por precios públicos se contemplan aquellos que las comunidades establecen para las enseñanzas universitarias oficiales que se imparten en las universidades públicas. Del mismo modo, el grado de experimentalidad, hace referencia a la carga teórica y práctica de los programas docentes y, es por ello que, las carreras que tienen un elevado peso práctico están asociadas a un nivel de experimentalidad elevado. 
En este trabajo, exponemos resultados derivados del contraste directo entre los precios establecidos por las 17 Comunidades Autónomas. Para ello, utilizamos dos ejemplos de carreras universitarias clasificadas en experimentalidad mínima y máxima. Para el caso de la primera, hemos seleccionado los estudios de Grado en Derecho ya que esta carrera es ofertada en todas las comunidades (al menos en alguna de sus universidades) y por el hecho de que se contempla en el nivel de experimentalidad mínima prácticamente en todas las comunidades autónomas salvo en Asturias, Canarias, Extremadura y Cantabria. Así, en el caso de la comunidad asturiana, los estudios citados aparecen en el segundo grado de experimental de los tres que establece este territorio por lo que se ha fijado el precio que corresponde a dicho grado. En Canarias, se disponen en el tercer grado de los cuatro que se fijan y en Extremadura, en cuarta posición de las cinco experimentalidades que se marcan. Canarias hace una distinción por ramas de conocimiento e incluye a los estudios citados en Ciencias Sociales y Jurídicas, grado cuatro de los cinco que marca. Respecto a los estudios con carácter de grado máximo, hemos elegido los de Grado en Enfermería, también por ser la única carrera de experimentalidad máxima que aparece ofertada en todas las instituciones universitarias de las diferentes comunidades. Sólo el territorio de Castilla y León los clasifica en el grado de experimentalidad dos, de los cinco establecidos.

Aclarar también que cuando nos referimos a primera matrícula, estamos contemplando el precio establecido cuando es la primera vez que el alumno se matricula en esa materia. Aspecto que se va encadenado a un incremento de manera correspondiente cuando estamos hablando de segunda, tercera y cuarta matrícula.

\section{Resultados}

\subsection{Grado de experimentalidad. La llave que abre la puerta de la divergencia de costes}

Como ya hemos indicado, a partir del curso 2012/2013, cada comunidad autónoma agrupa las titulaciones en función de su experimentalidad y establece un precio público que es diferente para cada una de ellas. Se trata de una medida que no es nueva en nuestro país ya que tiene un carácter histórico. Bajo el amparo de la antigua Ley 8/1989, de 13 de abril, de Tasas y Precios Públicos, el entonces denominado Ministerio de Educación y Ciencia era el encargado de fijar la cuantía de los precios públicos y, ya distinguía entre enseñanzas experimentales y no experimentales, diferencia ésta que, obviamente, condicionaba el coste de los mismos. Con la descentralización administrativa, el traspaso de competencias a las Comunidades Autónomas, éstas han ido trazando su propia clasificación.

Es por ello que, en la actualidad, la categorización de las enseñanzas en función del grado de experimentalidad, es diferente entre los territorios autonómicos. En este sentido, autonomía y libertad de actuación dibujan un mapa que traza experimentalidades y precios asignados a cada uno de ellos de la manera más heterogénea y así se puede constatar en la tabla que mostramos a continuación.

Andalucía es la única comunidad que no ha optado por hacer una distinción experimental entre carreras a priori, ya que establece un precio público único en primera y segunda matrícula con independencia de la rama de conocimiento a la que pertenezcan los estudios. Sin embargo, cuando se trata de aplicar tasas en tercera y cuarta matrícula, sí realiza una distinción por grado de experimentalidad, concretamente, clasifica las carreras en cinco grados, aplicando los mismos precios en el primero, segundo y tercero, y reduciendo el 
precio del crédito cuando las carreras se encuentran en el cuarto y el quinto grado de experimentalidad. Galicia, Andalucía y Cantabria, no realizan una clasificación de las diferentes carreras, sino que, establecen ramas de conocimiento.

El resto de comunidades sí utiliza dicha herramienta clasificatoria y se observa cómo el establecimiento de niveles de concreción experimental se dispara en algunos territorios hasta el cinco. Particulares son los casos de Castilla y León y la Comunidad de Aragón ya que, el pasado curso, la primera, establecía siete grados de experimentalidad y, la segunda seis. Para este curso, han optado por reducir esa especificidad y acotar la expansión de la misma, igualándola al quinto y máximo nivel establecido. Introduce también Castilla y León la distinción entre carreras, dentro de los grados dos y tres de experimentalidad, aplicándoles diferentes precios (cuadro 2).

Cuadro 2. Nivel de experimentalidad de los estudios de grado y precio del crédito (en euros) según Comunidad Autónoma

\begin{tabular}{llccccc}
\hline \multirow{2}{*}{$\mathbf{1}$ NIVEL } & & $\mathbf{1}$ & $\mathbf{2}$ & $\mathbf{3}$ & $\mathbf{4}$ & $\mathbf{5}$ \\
\hline \multirow{3}{*}{ NIVELES } & Andalucía & 12,62 & & & & \\
& Galicia & 13,93 & 9,85 & & & \\
& Murcia (Región de) & 16,78 & 14,38 & & & \\
& Navarra (C. Foral) & 23,05 & 16,27 & & & \\
\hline \multirow{3}{*}{ NIVELES } & Asturias (Principado de) & 22,03 & 17,26 & 12,11 & & \\
& Cataluña & 39,53 & 35,77 & 25,27 & & \\
& Madrid (Comunidad de) & 26,81 & 25,18 & 21,94 & & \\
& Rioja (La) & 23,51 & 21,21 & 14,60 & & \\
\hline \multirow{4}{*}{ NIVELES } & Aragón & 23,39 & 21,66 & 16,20 & 13,70 & \\
& Canarias & 17,43 & 15,09 & 12,14 & 11,32 & \\
& Castilla la Mancha & 18,87 & 17,64 & 14,58 & 12,13 & \\
& País Vasco & 19,84 & 19,19 & 14,39 & 14,08 & \\
\hline \multirow{5}{*}{ NIVELES } & Balears (IIles) & 23,13 & 20,56 & 18,01 & 15,03 & 12,88 \\
& Cantabria & 16,07 & 15,02 & 12,62 & 11,14 & 10,28 \\
& Comunidad Valenciana & 23,15 & 22,18 & 17,95 & 16,37 & 15,17 \\
& Extremadura & 18,51 & 16,83 & 15,70 & 12,33 & 10,31 \\
& Castilla y León* & 30,25 & $27,72(\mathrm{~B} 1)$ & $24,17(\mathrm{C} 1)$ & 18,54 & 17,07 \\
& & $5,55(\mathrm{~B} 2)$ & $20,07(\mathrm{C} 2)$ & \\
\hline
\end{tabular}

Nota: * Se establecen dentro de esta comunidad, en el nivel 2 y 3, dos precios diferentes que se aplicarán en función de la carrera cursada. Eso significa que, dentro de un mismo nivel, se clasifican los estudios en dos grupos: $\mathrm{B} 1$ y $\mathrm{B} 2$ para nivel 2 y $\mathrm{C} 1$ y $\mathrm{C} 2$ para nivel 3 y, se le aplica precio diferente.

Fuente: Elaboración propia a partir de las Estadísticas Ministerio de Educación, Cultura y Deporte. Curso 2017/2018.

El cuadro 2 muestra los precios que se le otorgan a los créditos por comunidades y por grado de experimentalidad. Destacan Madrid, Cataluña, Castilla y León y Valencia por ser las que más disparan los precios del crédito tanto en la opción mínima como máxima, esto hace que, en estos territorios, el crédito de experimentalidad mínima alcance valores más altos que los correspondientes a la experimentalidad máxima establecidos por comunidades como Galicia, Murcia y Cantabria, entre otras.

Nótese que los grados de experimentalidad van desde el uno, que sería el mayor grado y, al que se le aplica el mayor precio, y el cinco que, sería el menor grado y al que se le asigna el precio menor. En este sentido, a medida que aumenta el grado de experimentalidad en 
número, disminuye el precio del crédito aplicado. El coste del crédito de las asignaturas contempladas en los grados, dos, tres, cuatro y cinco iría decreciendo.

\subsection{Cursar una misma carrera de grado tiene un coste diferente en función del territorio}

¿Cómo puede explicarse que un alumno no pague semejante precio por cursar los mismos estudios, pero en universidades situadas en comunidades diferentes? Parecería ésta una cuestión de respuesta obvia: a igual carrera, igual precio, independientemente del territorio en el que esté situada la institución en la que se cursan. Sin embargo, al cotejar los datos, que en este caso recoge el coste de la primera matrícula de un curso completo de 60 créditos ECTS, podemos constatar las diferencias existentes entre comunidades. Para el grado en Enfermería (experimentalidad máxima), muestra el gráfico 3, valores tan dispares como la diferencia de más de mil euros entre la comunidad catalana y la andaluza. $\mathrm{El}$ coste medio se establece en $\mathrm{X}=1283,071$ euros. De las diecisiete comunidades, en ocho de ellas el precio se fija por debajo y en nueve se hace por encima (figura 3 ).

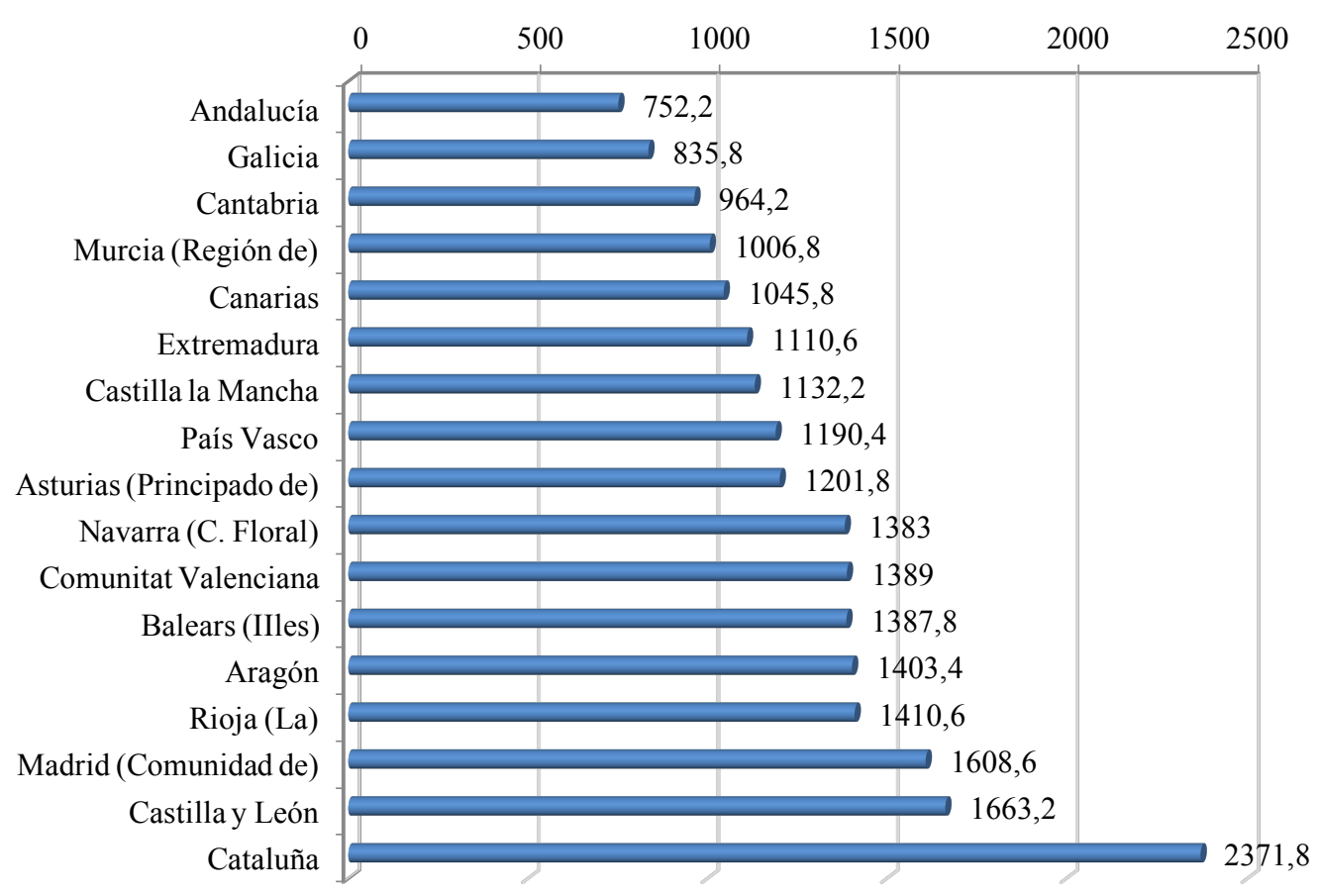

Figura 3. Precio en euros de un curso de 60 créditos ECTS en primera matrícula.

Experimentalidad máxima: Grado de Enfermería

Fuente: Elaboración propia.

Un alumno matriculado en estos estudios en el territorio catalán, pagaría 1619,6 euros más, es decir, un precio que supera en un $215 \%$ al que pagaría en la comunidad que marca los precios más baratos, que en este grado de experimentalidad es Andalucía. El gráfico 4 muestra el porcentaje en el que aumenta el coste de estos estudios por comunidades respecto al punto más barato. Vemos cómo, nuevamente, hay realidades que se alejan mucho del punto cero (Andalucía) y que se van posicionando dentro de la categoría de "las más caras" 


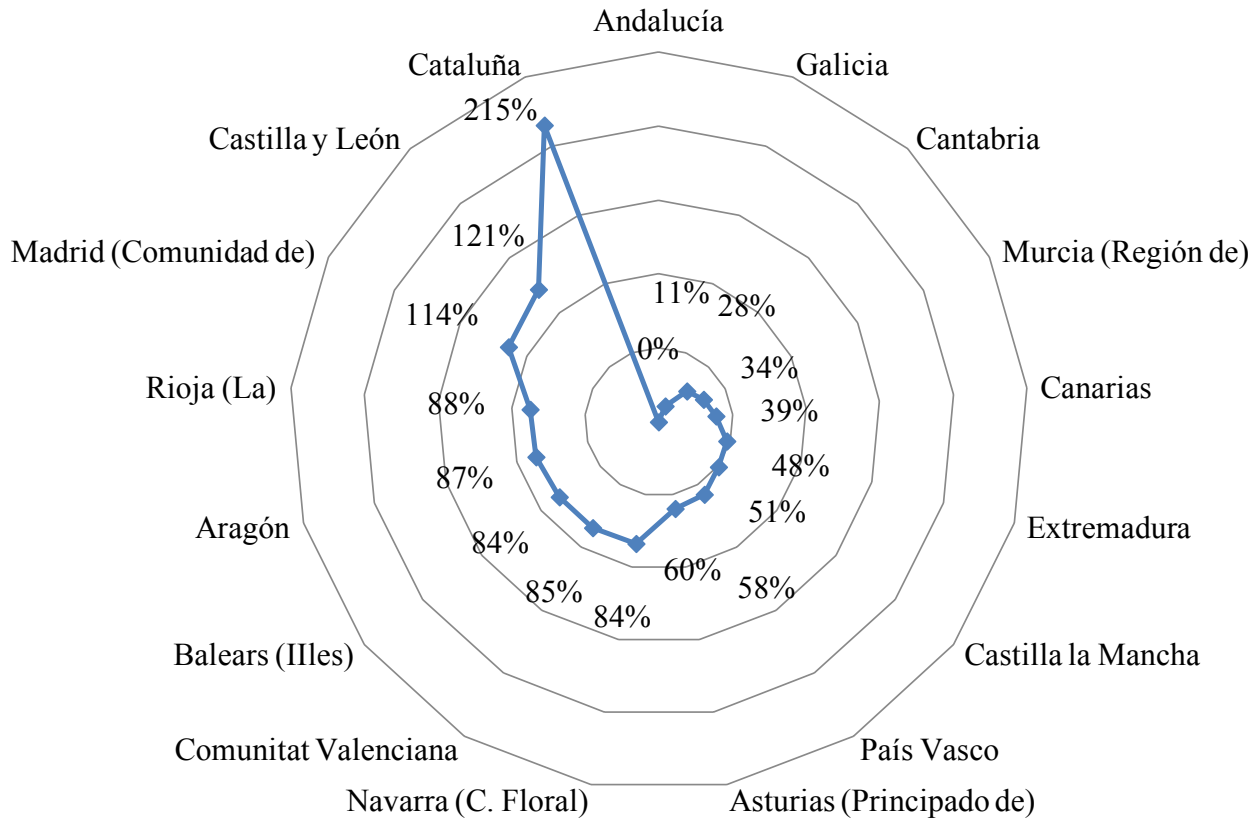

Figura 4. Porcentaje de aumento del coste de un curso de 60 créditos ECTS por Comunidad Autónoma. Estudios de Enfermería

Fuente: Elaboración propia.

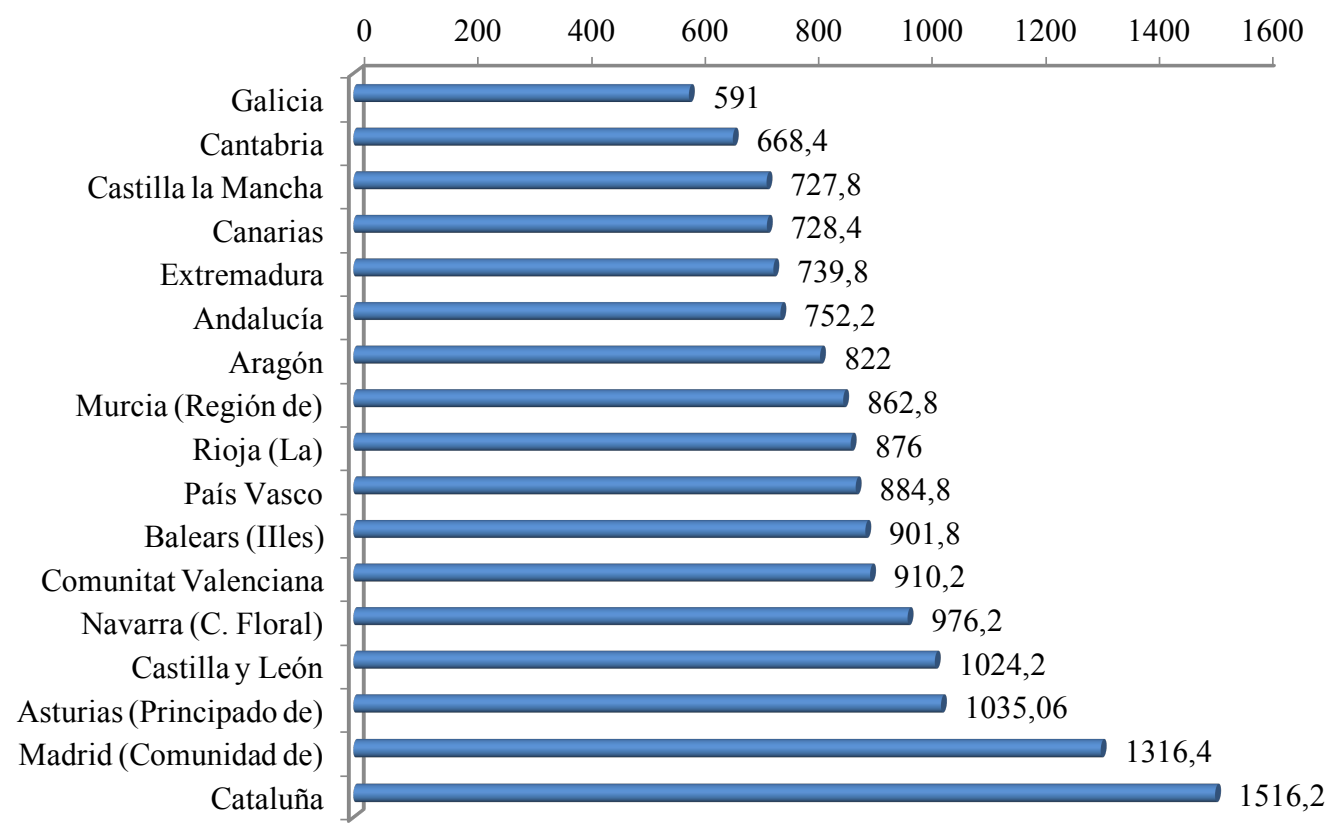

Figura 5. Precio en euros de un curso de 60 créditos ECTS en primera matrícula. Experimentalidad mínima. Grado en Derecho Fuente: Elaboración propia.

Respecto al grado en Derecho (experimentalidad mínima), tal y como recoge la figura 5 , cabe destacar igualmente la gran diferencia existente-aunque en este caso los precios son 
menores- entre comunidades, marcando los valores extremos máximos Cataluña y mínimos Galicia, con una divergencia de 952,2 euros entre una y otra. La media del precio total de la matrícula se establece en $\mathrm{X}=901,95$ euros. Once comunidades fijan su precio por debajo de dicha media y seis de ellas lo hacen por encima.

En este caso, al alumno que se matricula en territorio catalán cursar sus estudios le costaría un $157 \%$ más que si lo hace en la comunidad gallega que se presenta como la más económica. Muestra la figura 6 la posición de las diferentes autonomías respecto a ese punto. Se aprecian porcentajes moderados de aumento para Cantabria, Castilla la Mancha, Canarias Extremadura entre otras y los que superan el 50\% como Baleares, valencia y Navarra, Presencia destacada nuevamente de comunidades que van tomando posiciones entre "las más caras" como Madrid, Castilla y León y Asturias.

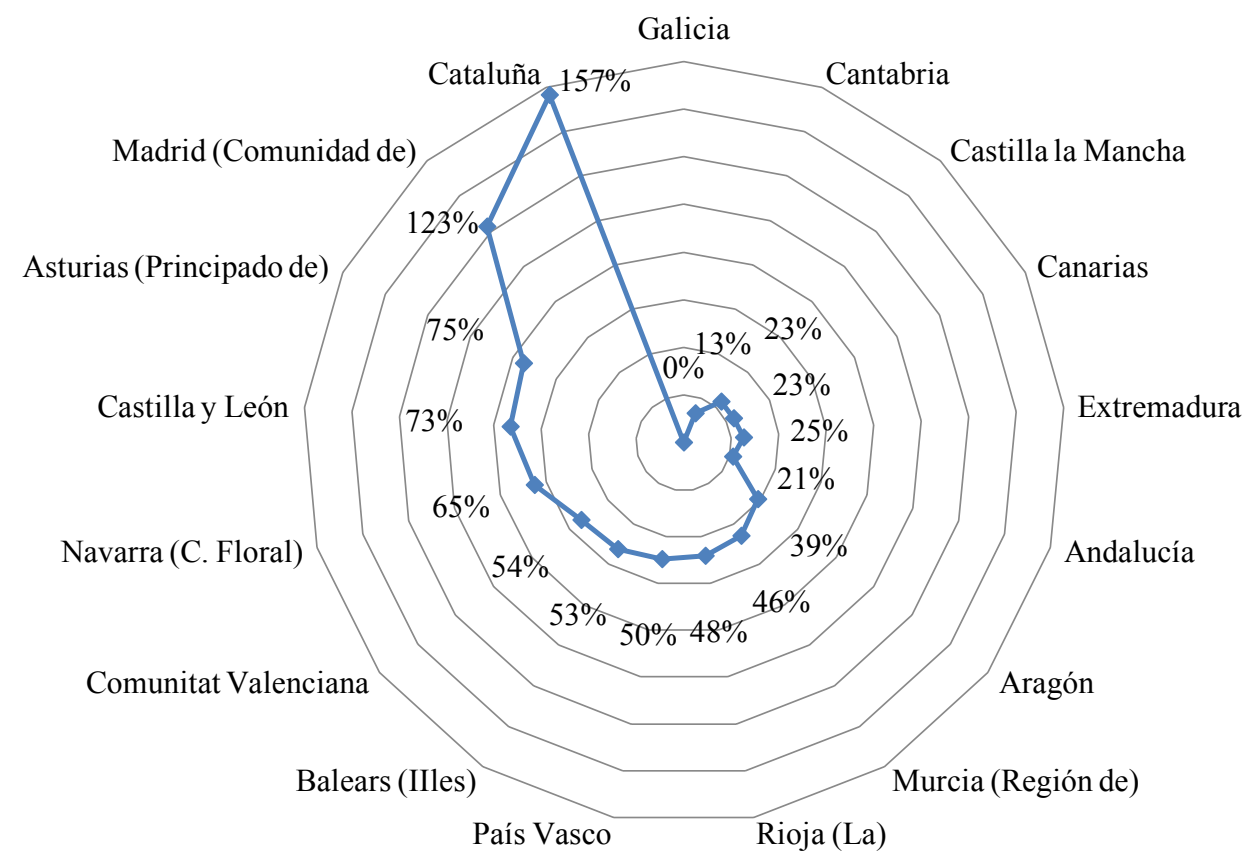

Figura 6. Porcentaje de aumento del coste de un curso de 60 créditos ECTS por Comunidad Autónoma. Estudios de Derecho

Fuente: Elaboración propia.

\subsection{Penalización económica al alumno "no eficiente"}

Venimos trabajando sobre el concepto de una educación superior cuya financiación es ampliamente pública pero que a su vez se contempla como un bien privado, a beneficio de las personas de manera individual, las cuales han de afrontar los costes totales de su enseñanza. Como ya hemos constatado, la nueva política de fijación de tasas académicas, no sólo se materializa en un aumento del precio del crédito matriculado, sino que también, utiliza el concepto "coste" como un mecanismo de penalización y persuasión para aquel alumno que no alcance los resultados esperados. Para el sistema, un estudiante que ha de matricularse en una asignatura tres o cuatro veces, es un "mal" discente y por ello, es 
"castigado", sin tener en cuenta sus circunstancias ${ }^{3}$, con un pago muy elevado de los créditos correspondientes a dicha materia. Se entiende que dicho alumno forma parte de una institución pública, al servicio de la sociedad, cuyos costes se asumen a través de la contribución, por medio de impuestos, de todos los ciudadanos y, por lo tanto, debe rendir cuentas a través de sus resultados. Y así lo justifican Escardíbul y Oroval (2011) al afirmar:

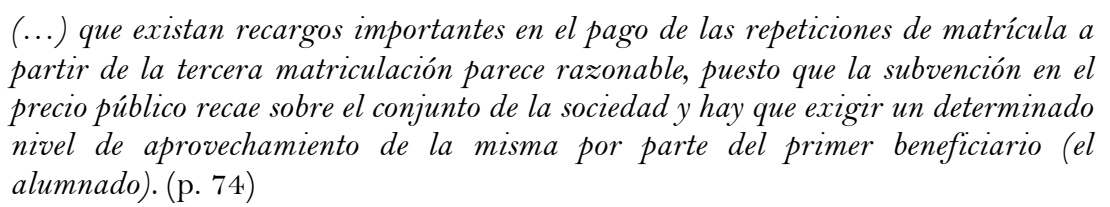

A continuación, la figura 7 constata la magnitud del incremento del precio del crédito que se produce en la cuarta matrícula con respecto al precio de la primera. Hablamos de valores que alcanzan en algunas comunidades, el 500\% de aumento.

Encontramos nuevamente diferencias significativas entre territorios. Comunidades como País Vasco (teniendo en cuenta que en este caso aplicamos los valores pertenecientes a la tercera matricula ya que no existe la posibilidad de una cuarta) y Galicia presentan los valores más bajos de incremento en el grado de experimentalidad máxima y mínima con alrededor del $118 \%$ y $185 \%$ respectivamente. El resto de comunidades se sitúan por encima del $350 \%$ de aumento salvo Cataluña que se mantiene en un $271 \%$.

Resalta el hecho de que la mayoría de territorios autonómicos asignan más o menos el mismo porcentaje de aumento para ambos grados de experimentalidad, si bien, la comunidad andaluza se desmarca de esta regla general aumentando el incremento de la experimentalidad máxima en un 61,20\% por encima de la mínima a la que se suma Aragón $(+32,76 \%)$. Madrid $(+9,30 \%)$ y País Vasco $(+1,96 \%)$ incrementan el coste de los estudios en la modalidad mínima en porcentajes superiores a los que aplican para el caso de la máxima, aunque, como vemos, en el caso de la comunidad vasca el aumento no llega a dos puntos.

Especial interés merece el análisis del incremento en euros que se produce entre el precio del crédito de la segunda matrícula con respecto a la primera. Remarcamos este hecho ya que, es un aspecto a cuidar cuando estamos hablando de equidad, el procurar que el coste de la segunda matrícula no se aleje demasiado del de la primera, lo que perjudicaría a estudiantes de rentas bajas al no poder hacer frente a este incremento, a pesar de la existencia de las ayudas al estudio (que, como sabemos, se han endurecido los criterios de acceso a las mismas), viéndose doblegados, en el peor de los casos, al abandono de dichos estudios.

Galicia vuelve a resaltar por ser la comunidad que menos euros incrementa el precio del crédito $(5,37 €$ máxima y 3,77 € mínima) seguida de Cataluña $(9,29 €$ máxima y 5,94 € mínima) y País Vasco (8,76 € máxima y 6,4 € mínima). Aragón hace un incremento menor en la especialidad mínima $(6,74 €)$ sin embargo en la máxima hace un incremento por encima de la media $(14,06 €)$. Los valores de aumento del coste se sitúan por encima del $50 \%$ en la mayoría de comunidades siendo el $100 \%$ el máximo porcentaje que se sube. Tal y como refleja la figura 8 , existe una constante en el porcentaje de aumento entre

\footnotetext{
${ }^{3}$ Cabe destacar aquí que si bien ya la estrategia EU 2015 apelaba al hecho de tener en cuenta la situación de los alumnos que cursaran sus estudios a tiempo parcial (por cuestiones de trabajo), en la práctica, no se establecen medidas que los diferencie del resto del alumnado y son sometidos al mismo sistema de penalización.
} 
experimentalidades, salvo en el caso de la región Balear en el que se constatan disfunciones importantes en este sentido. Así, en la experimentalidad máxima se manejan cifras del $55 \%$ de aumento y éstas se disparan al $100 \%$ para el caso del grado mínimo. Hecho que, como hemos visto se produce también en Aragón, pero de manera más moderada.

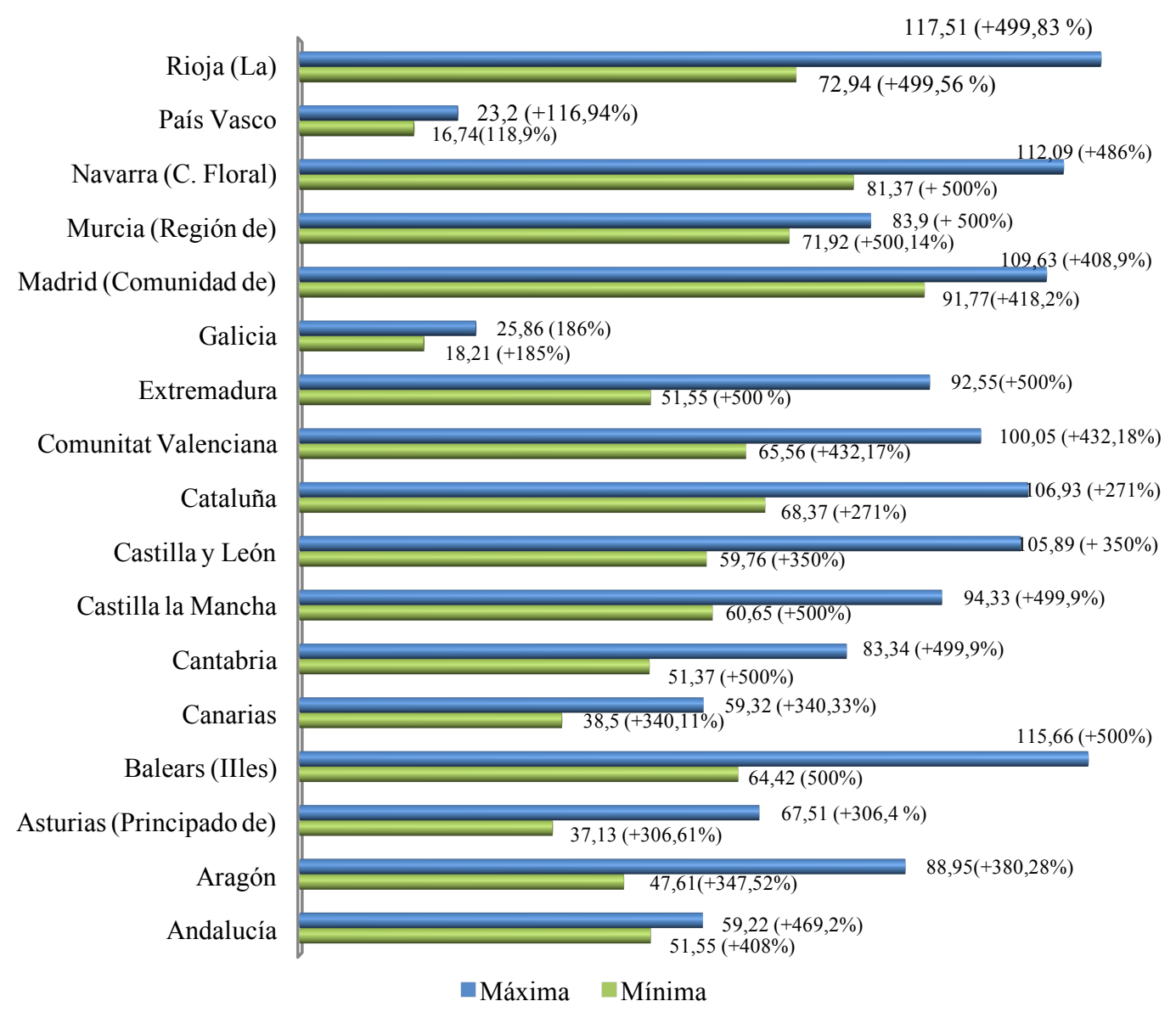

Figura 7. Diferencia en euros del precio del crédito en cuarta matrícula con respecto al precio del crédito de primera matrícula, en máxima y mínima experimentalidad Fuente: Elaboración propia.

Si aplicamos los precios que venimos manejando, al coste de una asignatura de 6 créditos ECTS y los comparamos entre sí, teniendo en cuenta el número de matrícula que se le aplique, podemos comprobar, de una manera muy gráfica, el total de cada serie y la proporción que ocupa con respecto a ese total. Así, la figura 9, muestra estos totales con respecto a una asignatura de los estudios de experimentalidad máxima, grado en enfermería. Se aprecian los picos elevados de comunidades como Navarra y Madrid para la primera y segunda matrícula, y llama especialmente la atención cómo la franja de la tercera y cuarta matrícula, aumentan su proporción con respecto al total. Nuevamente, se producen altos picos de precios tanto en la tercera como en la cuarta matrícula en determinadas comunidades. Los valores mínimos los encontramos en Galicia (187,26 €y 238, $74 €$ en tercera y cuarta matrícula), se trata de precios que varían considerablemente con respecto a comunidades como Castilla y León (589,92 € y 816,84 €), Navarra (599,04 $€$ y $810,84 €)$, Madrid $(592,5 €$ y $818,64 €)$, Islas Baleares $(600,96 €$ y 832,74 $€$ ) y la Rioja $(611,1 €$ y $846,12 €)$, ésta última aplica la cantidad más alta. Ello supone que si un alumno 
ha de matricularse por cuarta vez de una sola asignatura en estas comunidades le costaría más o menos lo mismo que un curso entero (en primera matrícula) en las universidades de las comunidades gallega y andaluza.

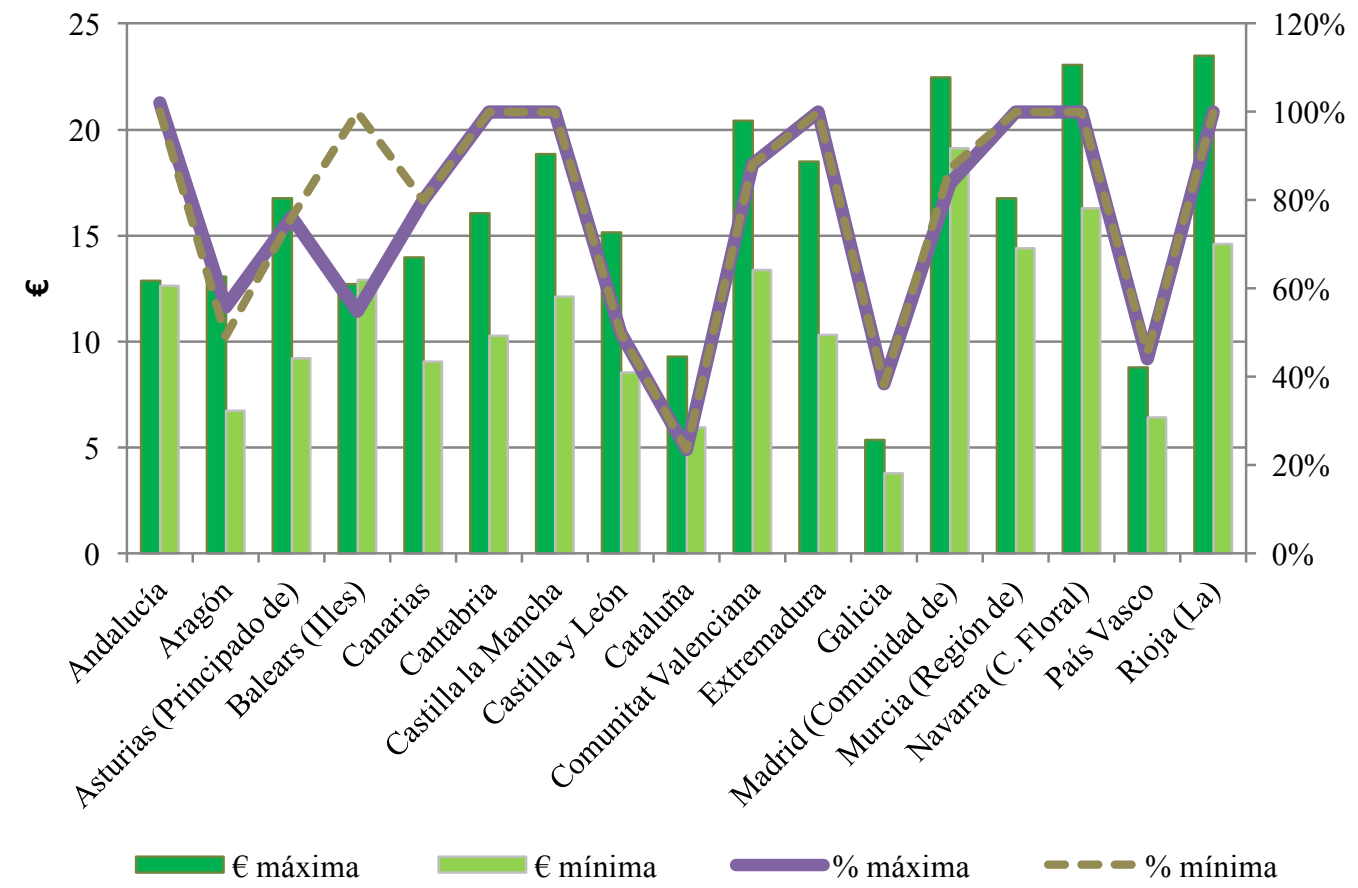

Figura 8. Porcentaje de incremento en euros por crédito de la $2^{\mathrm{a}}$ matrícula con respecto a la $1^{\text {a }}$. Experimentalidad máxima y mínima Fuente: Elaboración propia.

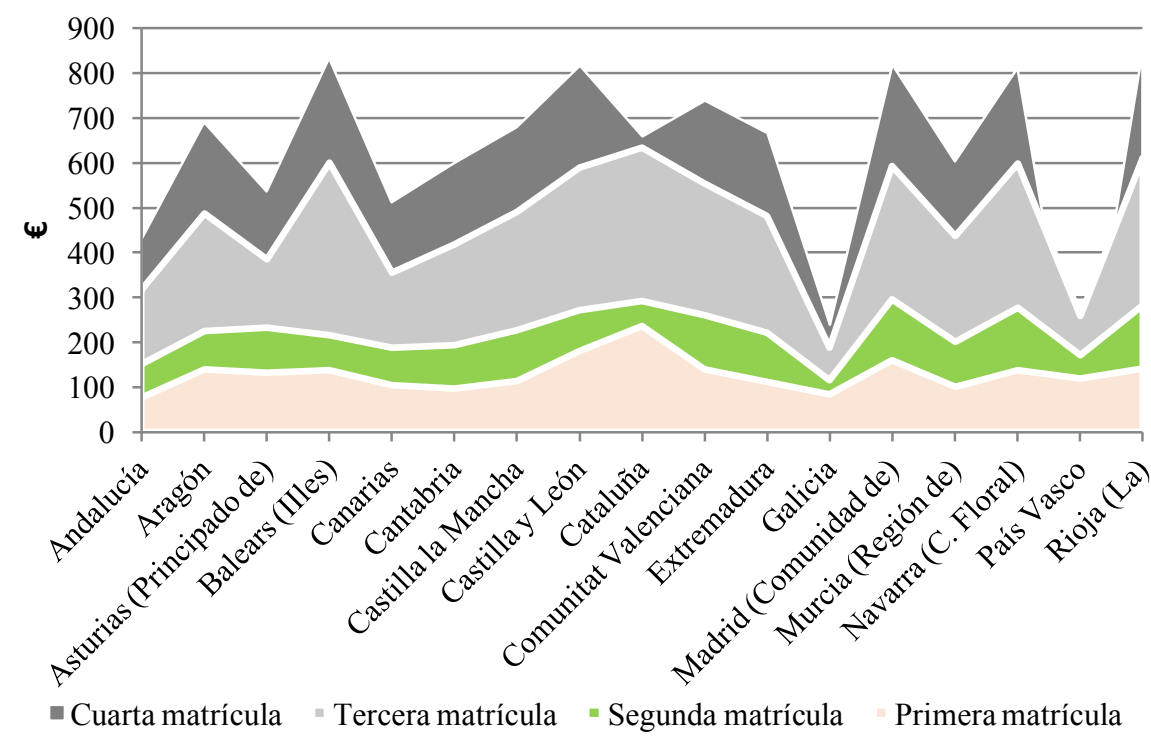

Figura 9. Coste de asignatura de 6 créditos ECTS según matrícula experimentalidad máxima. Grado de Enfermería

Fuente: Elaboración propia. 
Realizando el mismo cotejo para el caso de una asignatura de 6 créditos ECTs de los estudios del Grado en Derecho, experimentalidad mínima, nuevamente podemos comprobar a través de los datos expuestos en la figura 10, la notable diferencia de aumento en el coste que presenta la serie tercera matrícula con respecto de la primera y segunda.

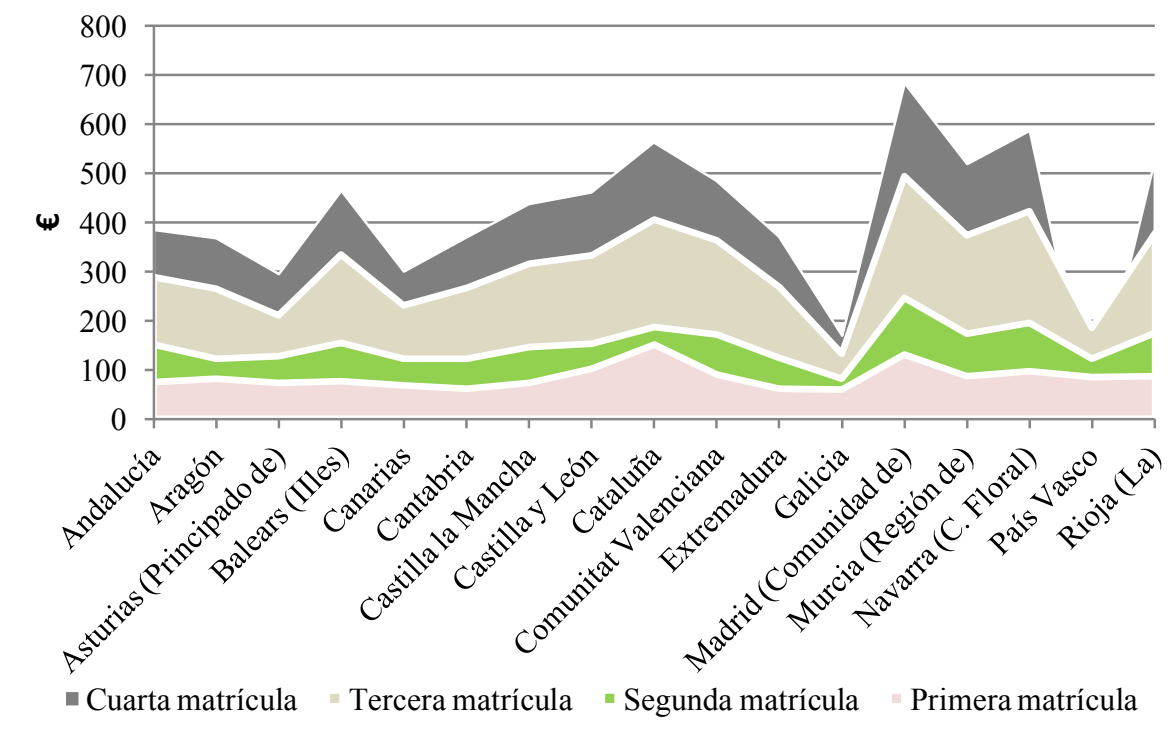

Figura 10. Coste de asignatura de 6 créditos ECTS según matrícula experimentalidad mínima. Grado de Derecho

Fuente: Elaboración propia.

Los picos de la tercera y cuarta matrícula se ven disparados significativamente en varias regiones como en Castilla y León (332,94 € y 460,98 €), Islas Baleares (334,74 € y 463,8 $€)$, Valencia (363,3 € y 484,38 €), Murcia (373,92 € y 517,8 €), la Rioja (373,92 € y 517,8 $€)$, Cataluña $(405,78 €$ y $561,84 €)$, Navarra $(413,58 €$ y $572,64 €)$ y, en la cumbre, la comunidad de Madrid (493,8 € y 682,26 €). De nuevo, se constata que Galicia es la comunidad más barata $(132,24 €$ y 168,36 €) con 361,56 y 513,9 euros de diferencia con respecto a Madrid, la más cara.

\section{Discusión y conclusiones}

¿Quién paga y quién debería pagar la educación superior pública? Abrimos este apartado de discusión con un interrogante que no es para nada novedoso. Sabemos que el tema que nos ocupa despierta interés no sólo en el caso español, sino que este asunto ha sido planteado por la mayoría de países. Albert y Roig (2011) en su trabajo sobre la financiación de la educación superior ya se planteaban esta y otras cuestiones que giraban alrededor de los desafíos financieros de una educación superior de masas, sugiriendo que "las instituciones de educación superior, no se financien sólo con recursos públicos, sino que también intervengan en su financiación recursos privados" (p. 26). La diversificación de las fuentes privadas de financiación no va a suponer que la universidad española pierda su esencia de institución pública, pero, los imperativos de la nueva economía del conocimiento sí le instan a la reformulación de las fuentes privadas tradicionales y, a la búsqueda de nuevos horizontes financieros. Y así lo constatan autores como Pérez y Vaquero (2011) al resaltar que "en Europa las fuentes de financiación privada que 
mayormente se están reformulando son los precios de matrícula y la financiación filantrópica" (p. 41).

En este sentido, España ha optado por instaurar un sistema de descentralización autonómica que refuerza el establecimiento de cuasi mercados educativos, potenciando la competición entre instituciones por la obtención de financiación tanto pública como privada. La introducción de mecanismos de mercado en el funcionamiento de los servicios públicos, supone una apertura hacia el negociado del establecimiento del precio público entre proveedor y comprador y no tanto teniendo en cuenta los criterios de oferta y demanda. Así, la educación superior se presenta como un bien de consumo, que puede proporcionar a los estudiantes, futuros trabajadores, ventajas competitivas, no sólo de cara al mercado laboral sino también ante la obtención de una posición tanto económica como social.

El nuevo modelo de fijación de precios públicos de los estudios universitarios, abre una horquilla y establece diferencias muy significativas entre comunidades que utilizan dicho modelo como instrumento de distinción. Y es que la lógica de precios impuesta por el financiamiento compartido, impulsa al alza los precios de los establecimientos que se contemplan como buenos a la vez que refuerza la idea de entidades baratas ligadas a baja calidad educativa. Con ello, no estamos afirmando que exista en la práctica una relación directa entre los binomios caro y calidad, y barato y mala calidad, pero sí que, con ello, se pretende reforzar esa idea. Igualmente, resulta significativa la relación entre precios fijados y oferta y demanda. $¿$ Existe esa diferencia de precios entre carreras ya que algunas tienen más demanda que otras?, ¿ đlas más caras son las más demandadas?, ¿las más baratas las menos? En el trabajo hemos utilizado principalmente la diferencia experimental a sabiendas que es un factor que determina este modelo, pero no el único. El grado de experimentalidad fijado se ha vinculado directamente con el coste real de los estudios y esta es una variable que va a explicar el que existan tantas diferencias entre comunidades

Debemos incluir en este coste todos los gastos asociados a estudiar, que no son sólo las tasas que se cobran directamente por derecho de matrícula y otros ligados a cuestiones de residencia y manutención. El principal coste que asume un estudiante y su familia está ligado a la falta de oportunidad de obtener ingresos económicos por no incorporarse al mercado de trabajo y dedicar varios años de su vida a estudiar. Cierto es que, un sistema de becas generador de equidad debería compensar este coste de oportunidad a los estudiantes y sus familias. Y no menos cierto es que, se debate sobre dicho sistema a la vez que es sometido a un sinfín de críticas, cuestionando su viabilidad. Ya destacamos en la introducción la conveniencia de relacionar los precios públicos fijados con la política de becas y ayudas al estudio que, podrían o no neutralizar o reducir, el impacto de los precios elevados y desiguales sobre las oportunidades de estudiantes y de familias en desventaja económica. A la par, resultaría muy útil, estudiar los efectos que este modelo de financiación tiene sobre la movilidad de los estudiantes, contemplada, ésta como un elemento clave en la formación y en la calidad educativa. ¿El criterio económico frena la movilidad estudiantil y especialmente la internacional?

Parece lógico, e incluso se puede afirmar abiertamente a la luz de los datos que, este sistema actual, donde todos los estudiantes pagan prácticamente lo mismo, independientemente de la renta familiar, no genera suficiente equidad. Constatado queda el factor de penalización que se vislumbra en el encarecimiento de la tercera y cuarta matrícula. Un aspecto que relacionamos directamente con las normas de progreso y 
permanencia estudiantil establecidas por cada universidad. Llama la atención que, por un lado, la universidad en España sea muy permisiva (en criterios académicos) en cuanto a la permanencia del alumno cursando estudios y, por otro, se establezca un precio muy superior por la matrícula de esas asignaturas que no se han superado: si pagas, permaneces en el sistema.

De cualquier forma, lo que sí está claramente demostrado es que la vía de financiación privada de las instituciones universitarias, proveniente de las tasas pagadas por los discentes, ha experimentado un repunte importante en los últimos años. Las instituciones cuentan con esta fuente de ingresos y los alumnos y familias pueden elegir la institución dónde estudian no tanto por cuestiones puramente académicas sino por razones económicas. La libertad de elección conlleva el empoderamiento de las familias que, con sus recursos económicos, deciden dónde se forman sus hijos y lo que pagan por esa educación, todo ello dentro de un contex to de servicio público que, en muchos casos puede llegar a confundirse con un mercado privado en el que existe una gran variedad de servicios educativos a distintos precios. Obviamente, esta diversidad de precios nos hace pensar y nos lleva a discutir si realmente esta variedad nos permite elegir o tal vez nos conduce directamente a una segregación, obligando a cada quien a optar por el servicio educativo que pueda asumir en función de su condición económica. Los efectos regresivos sobre la equidad en el acceso a la educación superior y en la continuación de los estudios, en perjuicio de los estudiantes de sectores sociales desfavorecidos, es evidente en este modelo.

\section{Referencias}

Aguilá, S. (2016). En busca de la suficiencia financiera en la universidad pública española. De la financiación al control y gestión de costes. Intangible Capital, 12(1), 17-50.

Albert, C. y Roig, J. M. (2011). La financiación de la educación superior. En MECD (Ed.), Lecturas sobre economía de la educación. Homenaje María Jesús San Segundo (pp. 17-31). Madrid: Ministerio de Educación.

Canosa, J. (2007). Universidades norteamericanas, universidades europeas. Recuperado de: https://www.libertaddigital.com/opinion/ideas/universidades-norteamericanasuniversidades-europeas-1276233507.html

CCOO. (2016). Los precios de las matrículas universitarias, becas, ayudas y beneficios fiscales en Europa. La evolución de los precios públicos del sistema universitario español entre 2011 y 2016. Recuperado de http://www.feccoo-madrid.org/comunes/recursos/25/2227033Estudio_de_precios_publicos_universitarios.pdf

Daza, S., Subreenduth, S., Rhee, J. y Proctor, M. (2015). Funding re/de/form in higher education: Diverse points of engagement. En K. M. Sturges (Ed.), Neoliberalizing educational reform: America's quest for profitable market-colonies and the undoing of public good (pp. 149-184), Rotterdam: Sense Publishers.

Escardíbul J. O. y Oroval, E. (2011). Análisis del sistema actual de precios públicos y ayudas al estudio en la universidad española y de su previsible evolución. En MECD. (Ed.), Lecturas sobre economía de la educación. Homenaje María Jesús San Segundo (pp. 61-77). Madrid: Ministerio de Educación.

Escardíbul, J. O. y Pérez, C. (2013). La financiación de las universidades públicas españolas: Estado actual y propuestas de mejora. Revista de Educación y Derecho, 8,1-17. 
Escardíbul J. O., Morales, S., Pérez, C. y de la Torre, E. (2013, julio). Evolución de los precios de matrícula en las enseñanzas universitarias por comunidades autónomas (1992-2013). Un análisis antes y después del espacio europeo de educación superior. Comunicación presentada en las XXII Jornadas de la Asociación de Economía de la Educación. A Coruña.

Espejo, L. B. y Lázaro Herrero, L. (2016). La batalla por la gestión del conocimiento. El auge de la economía en la política universitaria española. Foro de educación, 14(21), 77-105.

Eurydice. (2011). La modernización de la educación superior en Europa: Financiación y dimensión social. Bruselas: Secretaría General Técnica.

Eurydice. (2016). National student fee and support systems in european higher education (2016/17). Eurydice facts and figures. Luxemburgo: Publications Office of the European Union.

Ferlie, E., Musselín, C. y Andresani, G. (2012) El pilotaje de los sistemas de educación superior: Una visión desde la perspectiva de la gestión pública. En B. Kehm (Comp.), La nueva gobernanza de los sistemas universitarios (pp. 133-173). Barcelona: Octaedro.

Fernández-González, N. (2016). Repensando las políticas de privatización en educación: El cercamiento de la escuela. Archivos Analíticos de Políticas Educativas, 24(123), 1-20. https://doi.org/10.14507/epaa.24.2509

Girotto, M., Mundet, J. y Llinás-Audet, X. (2013). Estrategia en la universidad: ¿Cuestión de calidad, gerencialismo y relaciones político-financieras? Revista de Educación, 361, 95-116.

Giroux, H. A. (2016). La educación superior y las políticas de ruptura. Revista EntramadosEducación y Sociedad, 3(3), 15-26.

Guerrero, S. (2012). Financiació i govern de les universitats públiques. Revista Catalana de Dret Públic, 44, 155-190.

Hernández, J. y Pérez, J. A. (2016). La universidad española en cifras 2014/2015. Madrid: Informe CRUE.

Informe CyD. (2015). Sistema universitario español. Rasgos básicos. Barcelona: Fundación conocimiento y desarrollo.

Kehm, B. M. (2012). Gobernanza: ¿Qué es? ¿Es importante? En B. M. Kehm (Comp.), La nueva gobernanza de los sistemas universitarios (pp. 19-48). Barcelona: Octaedro.

Lázaro Herrero, L. (2015). The future of Spanish public universities. The challenges of a discourse of excellence. Encounters in Theory \& History of Education/Rencontres en Theorie et Histoire de l'Educacion, 16, 146-164. https://doi.org/10.15572/enco2015.10

Llinás-Audet, X., Girotto, M. y Solé, F. (2011). La dirección estratégica universitaria y la eficacia de las herramientas de gestión: El caso de las universidades españolas. Revista de Educación, 355, 33-54.

López Segrera, F. (2009). Reflexiones en torno a la financiación actual y futura de las universidades a nivel mundial. Avaliação, 14(3), 523-56. https://doi.org/10.1590/S141440772009000300002

San Segundo, M. J. (1999). Financiación de la enseñanza universitaria: El papel de los precios a la luz de la experiencia internacional reciente. Revista de Educación, 318, 71-87.

Sanz-Magallón, G., Schwartz, P. y Morales, M. (2009). Hacia la transformación económica de la universidad española. Propuesta para la mejora de la financiación de la enseñanza superior. Revista Española de Pedagogía, 244, 445-460.

Schwartz, P. (2007). Nuevas opciones de financiación para la universidad española. Revista Principios, 9, 121-132. 
Verger, A. (2013). Políticas de mercado, estado y universidad: Hacia una conceptualización y explicación del fenómeno de la mercantilización de la educación superior. Revista de Educación, 360. Enero-abril, 268-291.

Verger, A. Bonal, X. y Zancajo, A. (2016). Recontextualización de políticas y (cuasi) mercados educativos. Un análisis de las dinámicas de demanda y oferta escolar en Chile. Archivos Analíticos de Políticas Educativas, 24(27), 1-22. https://doi.org/10.14507/epaa.24.2098

\section{Breve CV de la autora}

\section{Luján Lázaro Herrero}

Profesora en el Departamento de Teoría e Historia de la Educación de la Facultad de Educación en la Universidad de Salamanca. Doctora en Pedagogía por dicha universidad, con Premio Extraordinario de Doctorado y IV Premio Nacional Pedro Roselló otorgado por la Sociedad Española de Educación Comparada, SEEC. Sus líneas docentes e investigadoras se articulan a través de la Educación Comparada e Internacional, la Política Educativa y la Historia de la Educación. ORCID ID: https://orcid.org/oooo-0002-15593609. Email: lujan@usal.es 